\title{
Mangosteen leaf extract increases melanogenesis in B16F1 melanoma cells by stimulating tyrosinase activity in vitro and by up-regulating tyrosinase gene expression
}

\author{
MARIANI ABDUL HAMID ${ }^{1,2}$, MOHAMAD ROJI SARMIDI ${ }^{2}$ and CHANG SEO PARK ${ }^{1}$ \\ ${ }^{1}$ Department of Chemical and Biochemical Engineering, Dongguk University, Chung-Gu, Seoul 100-715, Republic of \\ Korea; ${ }^{2}$ Chemical Engineering Pilot Plant, University Teknologi Malaysia, 81310 Skudai, Johor, Malaysia
}

Received August 25, 2011; Accepted October 5, 2011

DOI: $10.3892 / \mathrm{ijmm} .2011 .840$

\begin{abstract}
Melanin synthesis is stimulated by various effectors, including $\alpha$-melanocyte stimulating hormone ( $\alpha$-MSH), cyclic AMP (cAMP)-elevating agents (forskolin, isobutylmethylxantine, glycyrrhizin) and ultraviolet light. Our investigation focused on the identification of the melanogenic efficacy of mangosteen (Garcinia mangostana) leaf extract with regard to its effects on melanogenesis in B16F1 melanoma cells, since it has been known to possess strong anti-oxidant activities. The mangosteen leaf extract was found to stimulate melanin synthesis and tyrosinase activity in a dose-dependent manner without any significant effects on cell proliferation. Cytotoxicity of the extract was measured using a 3-(4,5-dimethylthiazol2-yl)-2,5-diphenyltetrazolium bromide (MTT) assay; the highest concentration of the extract that did not affect cell viability was $32 \mu \mathrm{g} / \mathrm{ml}$. Formation of melanin from cultured B16F1 melanoma induced by extract treatment was estimated using spectrophotometry. In order to clarify the subsequent mechanism of tyrosinase activation by the extract, the levels of tyrosinase expression in $\mathrm{B} 16 \mathrm{~F} 1$ melanoma were examined
\end{abstract}

Correspondence to: Dr Chang Seo Park, Department of Chemical and Biochemical Engineering, Dongguk University, 3-26 Pil-Dong, Chung-Gu, Seoul 100-715, Republic of Korea

E-mail:dgucsp@dongguk.edu

Abbreviations: MTT, 3-(4,5-dimethylthiazol-2-yl)-2,5-diphenyl tetrazolium bromide; $\alpha$-MSH, $\alpha$-melanocyte stimulating hormone; FK, forskolin; MITF, microphtalmia-associated transcription factor; POMC, proopiomelanocortin; MC1R, melanocortin-1 receptor; PKC, protein kinase C; ACTH, adrenocorticotropic hormone; ATP, adenosine triphosphate; cAMP, cyclic adenosine mono-phosphate; CREB, cAMP response element binding protein; CRE, cAMP response element; DCT, dopachrome tautomerase; L-DOPA, L-3,4dihydroxyphenylalanine; b-HLH, basic-helix-loop-helix; TRP, tyrosinase-related protein; DPPH, 2,2-diphenyl-1-picrylhydrazyl; ERK, extracellular signal-regulated kinases

Key words: Garcinia mangostana, melanogenesis, melanin, tyrosinase, microphtalmia-associated transcription factor using an intracellular tyrosinase assay and tyrosinase zymography. Up-regulation of intracellular tyrosinase expression seemed to correlate with an increase in microphtalmia-associated transcription factor (MITF) protein levels since MITF is the key factor for genes involved in melanogenesis. Both of the results showed that tyrosinase activity was markedly enhanced from extract-treated cells. The overall results suggest that mangosteen leaf extract may be a promising candidate for the treatment of hypopigmentation disorder and useful for selftanning cosmetic products.

\section{Introduction}

Mangosteen (Garcinia mangostana L.) is a tropical tree native to Southeast Asia and is found predominantly in China, Cambodia, Indonesia, Malaysia, Thailand, Singapore, Taiwan and the Philippines. The mangosteen fruit is consumed fresh and can be processed into jams, preserves and candies. It is an important seasonal fruit consumed throughout South and East Asia and regarded by many as one of the best flavored in the world. Garcinia, an evergreen tree genus of the plant family Clusiaceae is native to tropical regions of the world; these include the purple mangosteen as one of possibly 300 species in the genus known for their edible fruits and rich pericalpal pigments. The mangosteen has also been used for nutritional and medicinal purposes for many centuries by these same countries to alleviate fever, diarrhea, headaches and heal wounds. The fruit rind has been used for internal and external infections treatment, and poultices can be used to treat skin condition; an extract of mangosteen pulp has even been used to control fever (1). The rind decoction is used to relieve cystitis, gonorrhea and gleet and is applied externally as an astringent lotion. Filipinos employ a decoction of the leaves and bark to treat thrush, diarrhea, dysentery and urinary disorders. In Malaysia, an infusion of the leaves, combined with unripe banana and benzene is applied to the wound of circumcision and a root decoction is taken to regulate menstruation. The dried mangosteen rind is use to treat dysentery, diarrhea and gonorrhea (1). Made into an ointment, mangosteen rind powder is used to treat skin disorders such as eczema. Mangosteen pulp and rind contain many antioxidants, which may have antitumor activity (2). 
Research results have shown that the mangosteen leaf extract possesses five active compounds, namely catechins, mangostin, normangostin, xanthones and gartanin (3). In recent years, mangosteen has attracted special attention for its xanthone, a particular class of plant phytochemical extracts from mangosteen, which is highly biologically active, possesses anti-inflammatory properties inhibiting cyclooxygenase (COX) enzymes, and have cardiovascular protective effects (4-8). Studies have demonstrated that prenylated xanthones are capable of treating tuberculosis (9). Of the xanthones tested, $\alpha$ - and $\beta$-mangostins, and also garcinone $B$, had the strongest inhibitory effects against mycobacterium, which are known to cause tuberculosis $(9,10)$. However, there have been no reports specifically addressing the effects of the mangosteen leaves on melanogenesis.

Melanogenesis is a biosynthesis pathway for melanin production from melanocytes located in the lowest layer of the human epidermis (9). UV-irradiation, a representative melanogenesis triggering factor, causes secretion of several melanogenic signaling delivery substances: proopiomelanocortin (POMC), a precursor of $\alpha$-melanocyte stimulating hormone ( $\alpha$-MSH), a receptor of $\alpha-\mathrm{MSH}$; melanocortin-1 receptor (MC1R); melanogenic enzymes; tyrosinase; tyrosinase-related protein-1 (TRP1); protein kinase C (PKC) from melanocyte $(12,13)$. In human epidermis, once $\alpha-\mathrm{MSH}$ and adrenocorticotropic hormone $(\mathrm{ACTH})$ are produced and released by keratinocytes after UV-irradiation $(14,15)$, they combine with their specific receptor MC1R and activate adenyl cyclase through G-protein, which converts adenosine triphosphate (ATP) to cyclic adenosine monophosphate (cAMP), leading to an increase in intracellular cAMP levels $(16,17)$. Cyclic AMP, generated from ATP, plays a role as a second messenger in the intracellular signaling pathway (18). When increased cAMP has an effect on PKA, the cAMP response element binding protein (CREB) and the cAMP response element (CRE), located in the $M$ promoter of the microphtalmia-associated transcription factor (MITF) gene, bind together (19). Cyclic AMP then undergoes melanogenesis, primarily via activation of MITF, thereby leading to induction of the expression of melanogenic enzymes (16). Increased expression of MITF leads to enhancement of the expression of genes for the melanogenic enzyme family, tyrosinase, TRP1, TRP2 and dopachrome tautomerase (DCT), which eventually stimulates melanin synthesis (20-22). Cyclic AMP-related biological effects depend on protein kinase A (PKA) and once PKA phosphorylates CREB, it interacts with CRE and increases the expression of the MITF genecontaining CRE, which is responsible for the DNA sequence in its promoter region $(18,23)$. Materials believed to cause an increase in intracellular cAMP are $\alpha-\mathrm{MSH}$, forskolin (FK), isobutyrylxanthine (IBMX), and dibutyryl cAMP (dbc AMP); these substances can be applied to pigment cells in human and mouse (18). Therefore, phytochemicals and other biomaterials that can modulate intracellular cAMP levels may also be able to regulate melanogenesis in human and mouse melanocytes (21).

The skin pigmentation processes involve de novo synthesis of melanin in melanocytes and the transfer of synthesized melanin packed in melanosomes to neighboring keratinocytes, which eventually turns the skin to a dark color $(24,25)$. Melanosomes contain three types of enzymes: tyrosinase;
TRP1; DCT (TRP2) (26). Tyrosinase is a rate-limiting enzyme involved in melanin synthesis that hydroxylates tyrosine, a kind of phenylalanine, to L-3,4-dihydroxyphenylalanine (L-DOPA) and oxidizes L-DOPA to dopaquinone $(2,27)$. Excessive accumulation of dopaquinone generated from hydroxylation and oxidation of tyrosine forms dopachrome, which conditionally exhausts cysteine, resulting in accumulation of the black and brownish pigment, eumelanin. Another type of melanin, pheomelanin, is produced through formation of 3- or 5-cysteinyldopa in the presence of cysteine (27-29). These three enzymes determine the types of melanin to eumelanin or pheomelanin (30). Accordingly, skin color can be determined by a ratio between the two types of melanin, the amount of each type of melanin, and the extent of transferring melanosomes to keratinocytes (22).

There are several diseases marked by a lack of pigment in the skin that are referred to as leukoderma; some are caused by an inability of the melanocytes to produce melanin, while others are caused by melanocytes either not being present or being destroyed (31). The latter are the pathology of the phenotypically similar piebaldism and the disease vitiligo $(31,32)$. Piebaldism exists during birth and is a lack of melanocytes in the skin, whilst vitiligo is a progressive disease, whereby the melanocytes are gradually destroyed, causing unpigmented areas on the skin (31).

In our search for a new potential treatment of hypopigmentation disorders in herbal medicine, we found the mangosteen leaf extract effective with regard to melanogenesis in B16F1 melanoma cells. The mangosteen leaf extract stimulates melanogenesis by up-regulating tyrosinase expression and microphtalmia-associated transcription factor (MITF) in B16F1 melanoma cells. In this study, the effects of the extract on melanogenesis were verified. The present study was also designed to gain insight into the role of the extract in melanogenic signaling in B16F1 melanoma cells.

\section{Materials and methods}

Materials. 3-(4,5-Dimethylthiazol-2-yl)-2,5-diphenyl tetrazolium bromide (MTT), $\alpha-\mathrm{MSH}$, dimethyl sulfoxide (DMSO), and FK were purchased from Sigma-Aldrich (St. Louis, MO, USA). Dulbecco's modified Eagle's medium (DMEM), fetal bovine serum (FBS), and penicillin-streptomycin were obtained from Welgene (Daegu, Korea). Antibodies against tyrosinase, MITF, and $\beta$-actin were purchased from Santa Cruz Biotechnology (Santa Cruz, CA, USA). Fresh mature mangosteen leaves were purchased from Toko Tenaga Keluarga Sdn Bhd, Johor, Malaysia. The selected leaves were from the division of Magnoliophyta, class of Magnoliopsida, family of Clusiaceae, genus of Garcinia L., and species of Garcinia mangostana. The entire leaves were carefully washed in water and immediately dried at a temperature of $45-50^{\circ} \mathrm{C}$ in a vacuum dryer for $8 \mathrm{~h}$ and stored at room temperature until future use. The dry leaves were further ground using a stainless-steel powder grinder PG-10 (SUS), with a driving motor $10 \mathrm{HP}$ and a fineness of 100 meshes.

Extraction of the mangosteen leaf extract. Extraction of the mangosteen leaves extract was performed as follows: $5 \mathrm{~kg}$ of dried mangosteen leaves were extracted in 80 liters of boiling 
water for $2 \mathrm{~h}$. After removal of the solids by filtration, the extracted solution was spray-dried using a pilot spray dryer (Niro A/S, GEA Group, Soeborg Denmark). The inlet and outlet temperature were 200 and $110^{\circ} \mathrm{C}$ respectively, with a feed capacity of $7 \mathrm{l} / \mathrm{h}$. The yield of the extract was obtained at $8 \%$ of the total raw material. The resultant powder was used for determination of the melanogenesis effect. Working solutions of the sample were prepared as follows: dried powder was dissolved in water to a final concentration of $1 \%(\mathrm{w} / \mathrm{v})$ and sterilized through filtration. The resulted filtrate was stored at $-20^{\circ} \mathrm{C}$.

Cell culture. B16F1 melanoma cells were obtained from the Korean Cell Line Bank (KCLB) and sustained in 10\% FBS and $1 \%$ penicillin-streptomycin supplemented DMEM. Incubation was carried out in $5 \% \mathrm{CO}_{2}$ incubator at $37^{\circ} \mathrm{C}$.

$\alpha-M S H$ and mangosteen leaf extract treatment. B16F1 melanoma cells were seeded at a density of $1.5 \times 10^{5}$ cells/well in 6-well plates containing DMEM supplemented with 10\% FBS and $1 \%$ penicillin-streptomycin. After $24 \mathrm{~h}$, the medium was substituted by a fresh medium supplemented with $5 \mathrm{nM}$ of $\alpha$-MSH, $10 \mu \mathrm{M}$ of FK, and different concentrations of mangosteen leaf extract $(4,8,16$ or $32 \mu \mathrm{g} / \mathrm{ml})$ and incubated for $48 \mathrm{~h}$. DMEM was used as a negative control, and $5 \mathrm{nM} \alpha-\mathrm{MSH}$ or $10 \mu \mathrm{M}$ FK (32) were used as positive controls.

MTT assay. The MTT assay is colorimetric assay for measuring the mitochondrial activity of enzymes that reduce MTT to formazan dyes, giving a purple color. A main application allows assessing the viability (cell counting) and the proliferation of cells (cell culture assays). It can also be used to determine cytotoxicity of potential medicinal agents and toxic materials, since those agents would stimulate or inhibit cell viability and growth. After $48 \mathrm{~h}$, the culture medium was removed and incubated with the MTT solution at $37^{\circ} \mathrm{C}$ for $90 \mathrm{~min}$. The solution was replaced with $0.04 \mathrm{~N} \mathrm{HCl-isopropyl} \mathrm{alcohol} \mathrm{solution,}$ with further incubation at room temperature for $30 \mathrm{~min}$. The harvested solution was centrifuged at 13,000 rpm for $5 \mathrm{~min}$. Absorbance of the supernatant was measured at $570 \mathrm{~nm}$ using a microplate reader (Perkin-Elmer, USA).

2,2-Diphenyl-1-picrylhydrazyl (DPPH) assay. Scavenging of DPPH free radicals is the basis of common antioxidant assays. A number of protocols have been followed for this assay resulting in a variation of results from different laboratories. DPPH is a common abbreviation for the organic chemical compound DPPH. It is a dark-colored crystalline powder composed of stable free-radical molecules. DPPH has two major applications, both in laboratory research, one as a monitor of chemical reactions involving radicals and the another as a standard of the position and intensity of electron paramagnetic resonance signals. The method using DPPH as a stable free radical to measure radical-scavenging activity has been widely used. Antioxidants react with DPPH, which are stable free radicals, and convert it to 1,1-diphenyl-2-(2,4,6-trinitrophenyl) hydrazine. The degree of discoloration indicates the scavenging potentials of the antioxidant compounds. DPPH was used to measure radical erasure capacity (anti-oxidative property) of various agricultural products. In this assay, DPPH (Sigma) was dissolved in ethanol at a volume of $250 \mu \mathrm{M}$, followed by sonication for $5 \mathrm{~min}$ to obtain the stable free radical DPPH (33). The test compound was diluted in DPPH solution at a ratio of 1:1. Appropriate controls were run in each series and fresh DPPH solution was prepared daily. Mangosteen leaf extracts were assayed in triplicate at five different concentrations, such that a 50\% decrease in DPPH absorbance could be calculated. Absorbance of the reaction mixture was measured after 20 min using a UV/V is spectrometer (DU730, Beckman Coulter, USA). The $\mathrm{FSC}_{50}$ (concentration causing 50\% radical scavenging activity) value of the mangosteen leaf extract was determined and compared with that of L-ascorbic acid and Trolox (all from Sigma).

Melanin assay. A secreted melanin assay was performed as described previously with slight modifications $(34,35)$. After $48 \mathrm{~h}$, the culture medium was harvested and centrifuged at $10,000 \mathrm{rpm}$ for $10 \mathrm{~min}$. Absorbance was measured at $405 \mathrm{~nm}$ using a microplate reader (Perkin-Elmer). The secreted melanin was expressed in a ratio calculated as follows: secreted melanin $(\%)=(\mathrm{C}-\mathrm{A}) / \mathrm{B} \times 100]$

In this formula, A represents absorbance value of the medium supplemented with each sample (before incubation), $\mathrm{B}$, the absorbance value of the untreated medium (harvested after $48 \mathrm{~h}$ of incubation), and $\mathrm{C}$, the absorbance value of the medium supplemented with each sample (harvested after $48 \mathrm{~h}$ of incubation). All values were obtained from measurements at $405 \mathrm{~nm}$.

Measurement of melanin content. The melanin content of the cultured melanoma was evaluated in accordance with the method described previously, with slight modifications (37). In brief, the cell pellets were solubilized in $10 \%$ DMSO, dissolved in $1 \mathrm{M} \mathrm{NaOH}\left(80^{\circ} \mathrm{C}\right)$, and boiled for $2 \mathrm{~h}$. Melanin concentrations were calculated by comparison of the OD at a wavelength of $400 \mathrm{~nm}$ and compared with a standard curve obtained from synthetic melanin. In order to determine the actual melanin formation from the same number of cells, the total melanin content of each pellet was divided by the number of melanoma cells. All of the measurements were performed in triplicate.

Intracellular tyrosinase activity assay. An intracellular tyrosinase activity assay was performed as described previously, with slight modifications $(13,27)$. After $48 \mathrm{~h}$, the culture cells were washed with PBS and harvested in RIPA cell lysis buffer supplemented with a protease inhibitor. The cell lysate was obtained after centrifugation at $13,000 \mathrm{rpm}$ for $15 \mathrm{~min}$. The amount of protein was calculated by a Bradford assay (BioRad, Hercules, CA, USA), using BSA as a standard (bovine serum albumin, Bio-Rad). The amount of each cell lysate was adjusted with lysis buffer to give the same protein concentration. L-DOPA $(10 \mu \mathrm{l})$ in sodium phosphate buffer $(10 \mathrm{mM})$ was added and incubated for $1 \mathrm{~h}$ at room temperature. Absorbance was measured at $475 \mathrm{~nm}$ using a microplate reader (PerkinElmer).

Tyrosinase zymography (L-DOPA staining). Tyrosinase zymography was performed as described previously (36). After $48 \mathrm{~h}$, the cultured cells were washed with PBS and harvested with RIPA cell lysis buffer supplemented with a protease 
Table I. Free radical-scavenging activity of mass content of antioxidants.

Antioxidant

Scavenging activity $\left(\mathrm{FSC}_{50}\right)$ concentration $(\mu \mathrm{g} / \mathrm{ml})^{\mathrm{a}}$

L-Ascorbic acid

Trolox

Mangosteen leaf extract (methanol) ${ }^{\mathrm{b}}$
$27.62 \pm 1.05$

$29.57 \pm 1.71$

$34.30 \pm 1.25$

${ }^{a}$ Each value is the mean $\pm \mathrm{SD}$ of three replicate assays. ${ }^{\mathrm{b}}$ Each value is the mean solvent of sample extract. $\mathrm{FSC}_{50}, 50 \%$ free-radical scavenging activity.
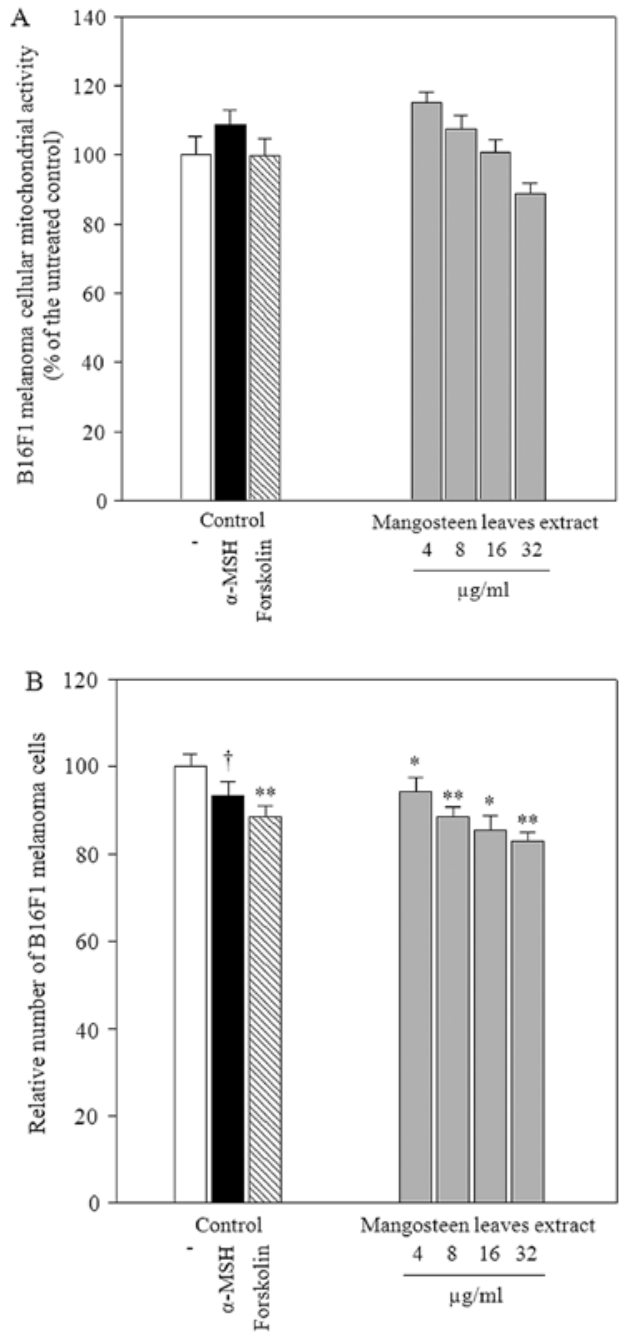

Figure 1. Mangosteen leaves extract has no detectable influence on B16F1 melanoma cellular mitochondrial activity. B16F1 melanoma cellular mitochondrial activity was validated through MTT assay method. (A) As showed in this figure, B16F1 melanoma cell viability was increased by mangosteen leaves extract treatment ranges at concentration of 4 and $8 \mu \mathrm{g} / \mathrm{ml}$. At the concentration of $32 \mu \mathrm{g} / \mathrm{ml}$, cell viability was shown to be $90 \%$ and decreasing rate of cell viability was grown according to the high concentration (data not shown). (B) The relative number of B16F1 melanoma cells after 2 days treated with mangosteen leaves extract. The number of melanoma cells decreased dose-dependently up to $32 \mu \mathrm{g} / \mathrm{ml}$ of ML extract treatment. Results are the average of three independent experiments $\pm \mathrm{SD}$. ${ }^{*} \mathrm{P}<0.05,{ }^{* *} \mathrm{P}<0.01$ compared to (+) $\alpha$-MSH control.

inhibitor. The amount of protein was also equilibrated as in the intracellular tyrosinase assay. Each sample mixed with the zymogram sample buffer was loaded onto $8 \%$ gel SDS-PAGE (sodium dodecyl sulfate polyacrylamide gel electrophoresis). After running, the gel was soaked twice in $0.1 \mathrm{M}$ sodium phosphate buffer for $30 \mathrm{~min}$. Staining was carried out with $10 \mathrm{mM}$ L-DOPA in $0.1 \mathrm{M}$ sodium phosphate buffer for $1 \mathrm{~h}$ at $37^{\circ} \mathrm{C}$.

Immunoblotting analysis. Once the cell lysates were prepared using a standard protocol, each sample was mixed with Laemmli sample buffer and denaturated at $85^{\circ} \mathrm{C}$ for $5 \mathrm{~min}$. Thereafter, samples were loaded onto $8 \%$ SDS-PAGE gels. After running, the gel was transferred to a PVDF membrane and blocked with 5\% skimmed milk. Anti-tyrosinase and antiMITF were used as primary antibodies and anti-goat IgG-HRP and anti-mouse IgG-HRP (all from Santa Cruz Biotechnology) as secondary antibodies. The antigen-antibody reaction was detected using an ECL solution system (Perkin-Elmer).

Statistical analysis. Statistical significance was assessed using the Student's t-test. All results were presented as the mean $\pm \mathrm{SD}$ of the combined data from replicate experiments.

\section{Results}

Mangosteen leaf extract possesses strong radical-scavenging activity. To evaluate the antioxidant activity of the mangosteen leaf extract, the DPPH assay was performed. The absorbance of the free-radical DPPH decreased when measured at $517 \mathrm{~nm}$ for five different concentrations and produced a color change, with colorization from violet to yellow. The $\mathrm{FSC}_{50}$ value determined for the extract was $34.30 \mu \mathrm{g} / \mathrm{ml}$ (Table I). The FSC $_{50}$ value of L-ascorbic acid and Trolox were 27.62 and $29.57 \mu \mathrm{g} / \mathrm{ml}$, respectively. The data indicate that the extract possesses a strong antioxidant capacity, comparable to that of L-ascorbic acid and Trolox.

Effects of mangosteen leaf extract on cell mitochondrial activity and relative number of cells, using cultured B16F1 melanoma cells. The cellular mitochondrial activity of cultured B16F1 melanoma cells was measured by an MTT assay. After 2 days of treatment, the mangosteen leaf extract (ML) showed no detectable adverse effects on cellular mitochondrial activity at concentrations between 4-32 $\mu \mathrm{g} / \mathrm{ml}$ (w/v) (Fig. 1A). The cellular mitochondrial activity was slightly decreased when the concentration of ML increased, however, the opposite pattern was observed for $\alpha-\mathrm{MSH}$, whereby the cellular mitochondrial activity of melanoma cells increased in comparison to the negative control. Based upon this observation, the experiments were performed within this concentration range. For the rela- 

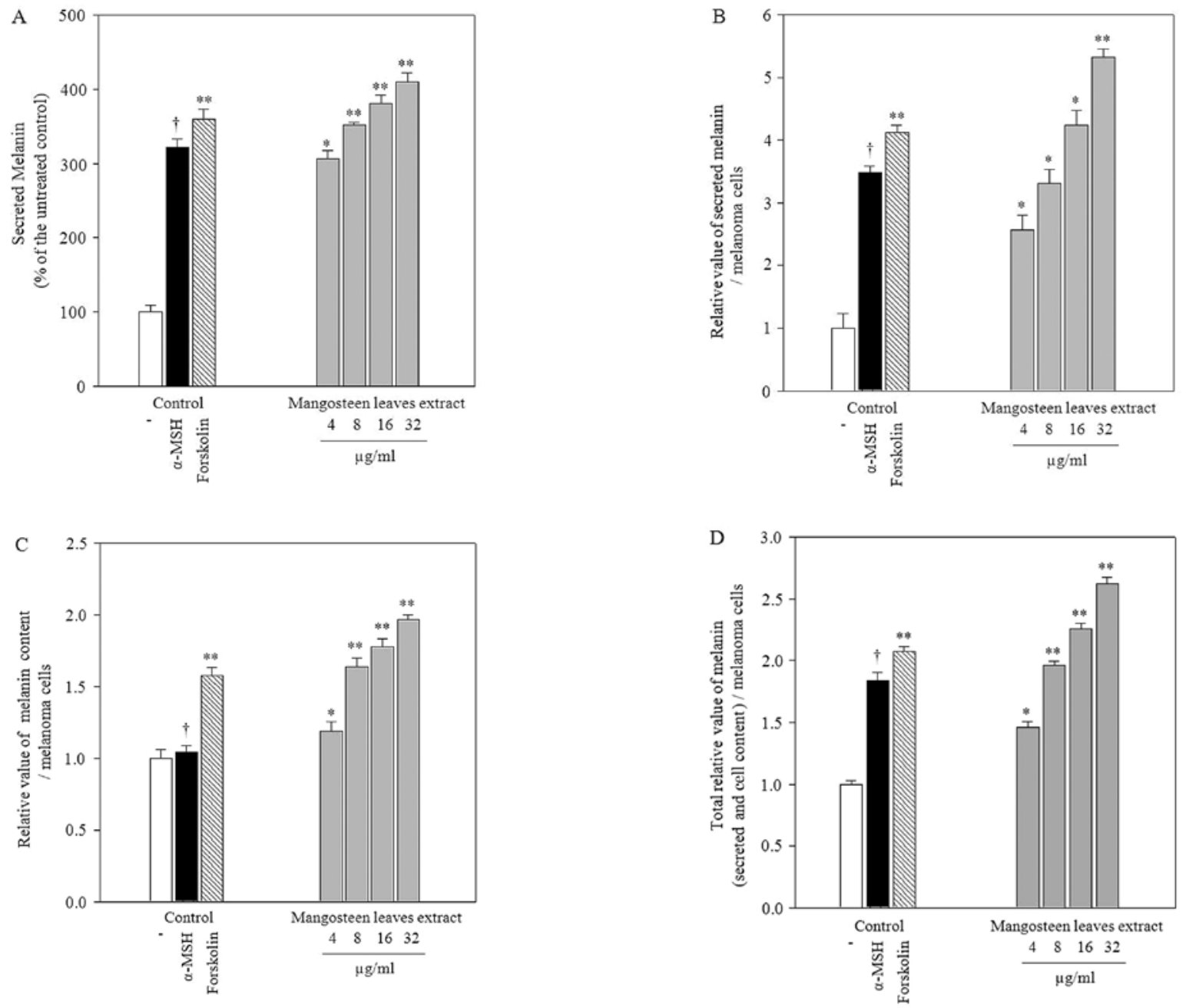

Figure 2. Melanin synthesis was increased by treatment with the mangosteen leaf extract. (A) The secreted melanin assay results show that the mangosteen leaf extract (ML) strongly increases melanogenesis in $\mathrm{B} 16 \mathrm{~F} 1$ melanoma cells. The effect of $16 \mu \mathrm{g} / \mathrm{ml} \mathrm{ML}$ was comparable to the $\alpha$-MSH-treated control and was 3 -fold higher compared to the negative control. The result of $32 \mu \mathrm{g} / \mathrm{ml}$ was more efficient than the $\alpha$-MSH-treated control and was 3.5 -fold higher compared to the negative control. This increment efficacy was apparently more effective than $5 \mathrm{nM}$ of $\alpha$-MSH or $10 \mu \mathrm{M}$ of forskolin (FK). Upon ML treatment, the melanin content increased in a dose-dependent manner up to $32 \mu \mathrm{g} / \mathrm{ml}$. (B) The relative number of the secreted melanin increased dose-dependently with increasing ML extract concentration. In agreement with the results from secreted melanin, the relative number of melanin of the individual melanoma cells increased up to 5.2-fold when treated with $32 \mu \mathrm{g} / \mathrm{ml}$ of the extract compared to the negative control. (C) The relative number of melanin content showed a similar pattern, with a dose-dependent increasing trend from the results obtained from secreted melanin. By treating with the highest concentration of the extract $(32 \mu \mathrm{g} / \mathrm{ml})$, the melanin content for each individual cell was found to be $\sim 2$-fold higher than the negative control. (D) The total melanin secreted into the culture medium and presented inside the cells of each individual B16F1 melanoma, revealed that FK demonstrated a very powerful melanogenic effect by inducing melanogenesis activity up to 2.1-fold and $\alpha$-MSH also showed significant effects of inducing such activity by nearly 2 -fold. ML showed even stronger melanogenic activity toward total melanin content and secretion, better than $\alpha-\mathrm{MSH}$ and FK. By treating with the maximum concentration of the extract ( $32 \mu \mathrm{g} / \mathrm{ml})$, the total melanin content and secretion for each individual cell was significantly boosted up to 2.7 -fold compared to the untreated control. Results are the average of three independent experiments $\pm \mathrm{SD}$. ${ }^{*} \mathrm{P}<0.05 ;{ }^{* *} \mathrm{P}<0.01$ compared to the positive $\alpha-\mathrm{MSH}$ control.

tive number of B16F1 melanoma cells, the authors examined whether ML could increase the number of B16F1 melanoma cells with up to 2 days of treatment. Based on the result from Fig. 1B, the relative number of B16F1 melanoma cells did not increase, but decreased after 2 days of treatment with ML.

Effects of mangosteen leaf extract on melanin secretion of B16F1 melanoma cells. In order to observe whether or not the mangosteen leaf extract induces melanogenesis, the amounts of melanin secreted into the culture medium and present inside the cells were determined. The melanin contents of B16F1 cells treated with different concentrations of ML extract were measured. Both $\alpha$-MSH and FK have been proven to be effective melanogenic agents, and were thus used as positive controls. Both $\alpha-\mathrm{MSH}$ and FK are also known as cAMPelevating agents (18), as cAMP pathway is one of the most pivotal signaling pathways in melanogenesis. In these experiments, cells were treated with ML $(4,8,16$ or $32 \mu \mathrm{g} / \mathrm{ml}), \alpha-\mathrm{MSH}$ $(5 \mathrm{nM})$, and FK $(10 \mu \mathrm{M})$ for 2 days, and then the amount of melanin secreted into the culture medium and present inside the cells were analyzed.

The secreted melanin content gradually increased after treatment with 4-16 $\mu \mathrm{g} / \mathrm{ml} \mathrm{ML}$, reaching a maximum value at the highest dosage (32 $\mu \mathrm{g} / \mathrm{ml})$ of ML (Fig. 2A). FK clearly demonstrated its powerful melanogenic activity by increasing the secreted melanin to the level of 3.5-fold of the untreated control, while $\alpha$-MSH also showed a significant increase in the melanin secretion (3-fold). The mangosteen leaf extract 

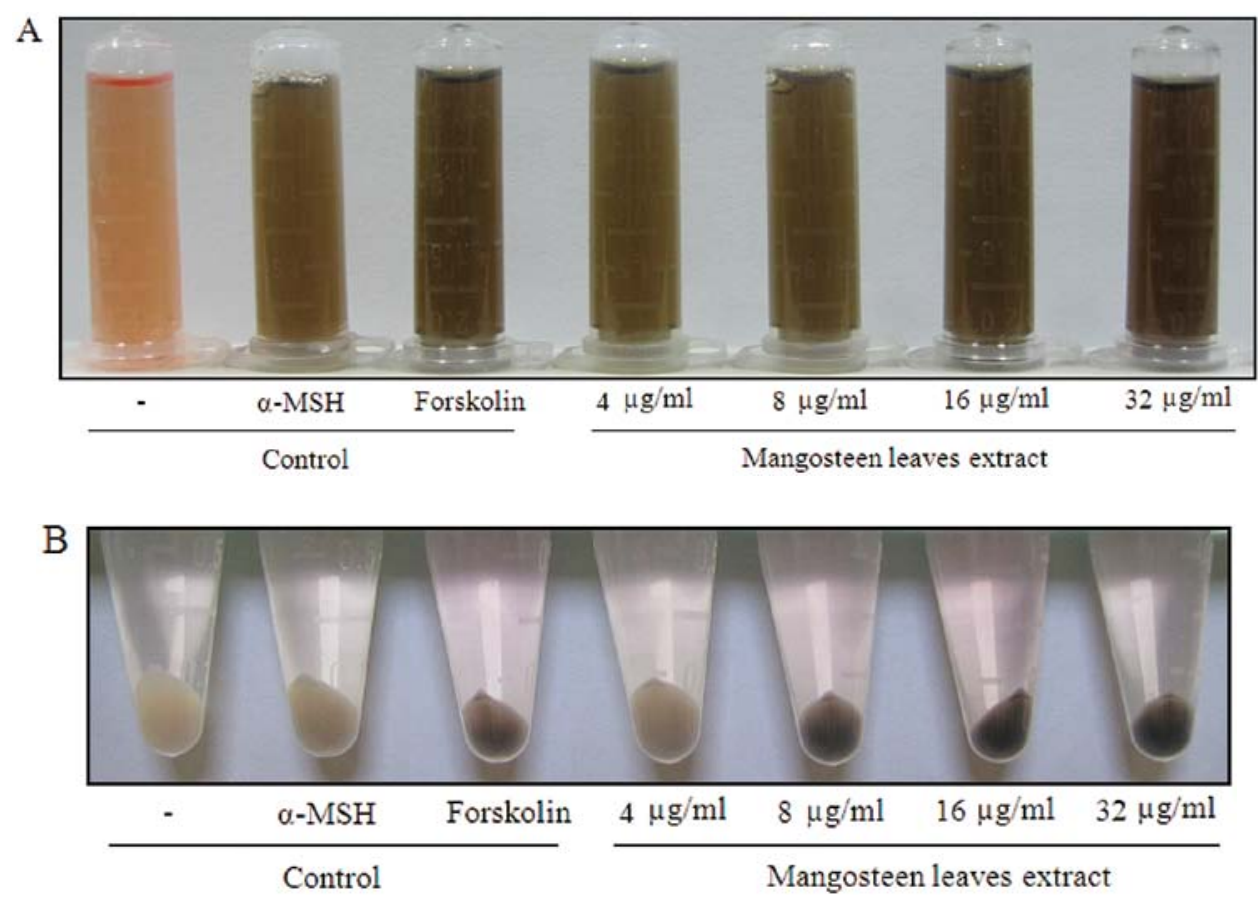

Figure 3. Mangosteen leaf extract increases melanogenesis in B16F1 melanoma cells. (A) Up-regulation of tyrosinase expression resulted in a dose-dependent increase in B16F1 melanoma cell media color from light-red to very dark brown. (B) The dark-black color of the B16F1 melanoma cell pellets demonstrate that $\alpha-\mathrm{MSH}$, forskolin, and the mangosteen leaf extract (ML) stimulate tyrosinase activity. Treatment with $5 \mathrm{nM} \alpha$-MSH resulted in a blacker and darker color of the B16F1 melanoma cell pellet. The color of the cell pellet was significantly blacker and darker after treatment with $10 \mu \mathrm{M}$ forskolin, compared to that of the negative control and $\alpha-\mathrm{MSH}$. Treatment with $32 \mu \mathrm{g} / \mathrm{ml}$ of the ML resulted in the blackest and darkest color for the B16F1 cell pellets compared to the other treated cells, showing that the ML dose-dependently increased melanogenesis activity.

showed even stronger melanogenic effects upon the secretion of melanin than FK and $\alpha$-MSH under these experimental conditions. Dose-dependent increment of the secreted melanin content was observed when treated with increasing amounts of ML extract. At $16 \mu \mathrm{g} / \mathrm{ml}$, the melanogenic effect of the ML extract on secreted melanin was very similar to that of $\alpha-\mathrm{MSH}$ and FK. The melanin secretion maximally increased when B16F1 melanoma cells were treated with $32 \mu \mathrm{g} / \mathrm{ml}$ of the extract (Fig. 2A), indicating that the extract might have prompted melanin synthesis within the cells. To further confirm whether the extract induced melanin secretion in $\mathrm{B} 16 \mathrm{~F} 1$ melanoma cells, the actual melanin value of the melanin secretion for each individual melanoma was examined. In agreement with the results of secreted melanin, the relative value of melanin of individual melanoma cells increased up to 5.2-fold when treated with $32 \mu \mathrm{g} / \mathrm{ml}$ of the extract when compared to the negative control (Fig. 2B). Treatment with $16 \mu \mathrm{g} / \mathrm{ml} \mathrm{ML}$, resulted in an actual value of the relative melanin similar and comparable with that with FK treatment, and even better than that with $\alpha$-MSH. Conversely, the relative value of melanin in B16F1 melanoma cells increased up to 3.5- and 4.0-fold, respectively.

Effects of mangosteen leaf extract on melanin content of B16F1 melanoma cells. To further clarify the effects of ML extract on melanogenesis, the amount of melanin inside the cells was assayed and the results obtained revealed that the melanin content for each individual melanoma cell dose-dependently increased by ML. As shown in Fig. 2C, treatment with the highest concentration of the extract $(32 \mu \mathrm{g} / \mathrm{ml})$, resulted in an $\sim 2$-fold increase in the melanin content compared to the negative control. No significant effect was observed upon treatment with $\alpha-\mathrm{MSH}$, thus indicating that $\alpha$-MSH significantly increased secreted melanin, but not melanin content of the B16F1 melanoma cells; however, FK demonstrated an increase in melanin content per cell, up to 1.6-fold compared to the untreated control, an effect similar to those in cells treated with $8 \mu \mathrm{g} / \mathrm{ml} \mathrm{ML}$. From this result, once again, the mangosteen leaf extract clearly demonstrated powerful melanogenic activity by markedly increasing the melanin content more than treatments with $\alpha$-MSH and FK.

The total melanin secreted into the culture medium and present inside the cells of each individual B16F1 melanoma cells revealed that FK demonstrated very powerful melanogenic effects by stimulating melanogenesis activity up to 2.1-fold (Fig. 2D); $\alpha$-MSH also showed significant effects on stimulating this activity by $\sim 2$-fold, even though the results obtained from assaying the melanin content were not as significant as those obtained by the secreted melanin assay. The mangosteen leaf extract showed even stronger melanogenic activity toward total melanin content and secretion than $\alpha$-MSH and FK. As predicted, by treating with the maximum concentration of the extract $(32 \mu \mathrm{g} / \mathrm{ml})$, the total melanin content and secretion for each individual cell were boosted significantly, up to 2.7-fold compared to the untreated control. By treating with 8 and $16 \mu \mathrm{g} / \mathrm{ml}$ of the extract, the total melanin content and secretion per cell were comparable and better than those treated with $\alpha-\mathrm{MSH}$ and FK. From these findings, it was confirmed that increase in melanin biosynthesis and secretion also resulted in a distinct and darkened coloration of the B16F1 melanoma media and black color of cells pellet (Fig. 3A and B). These observations suggest that 

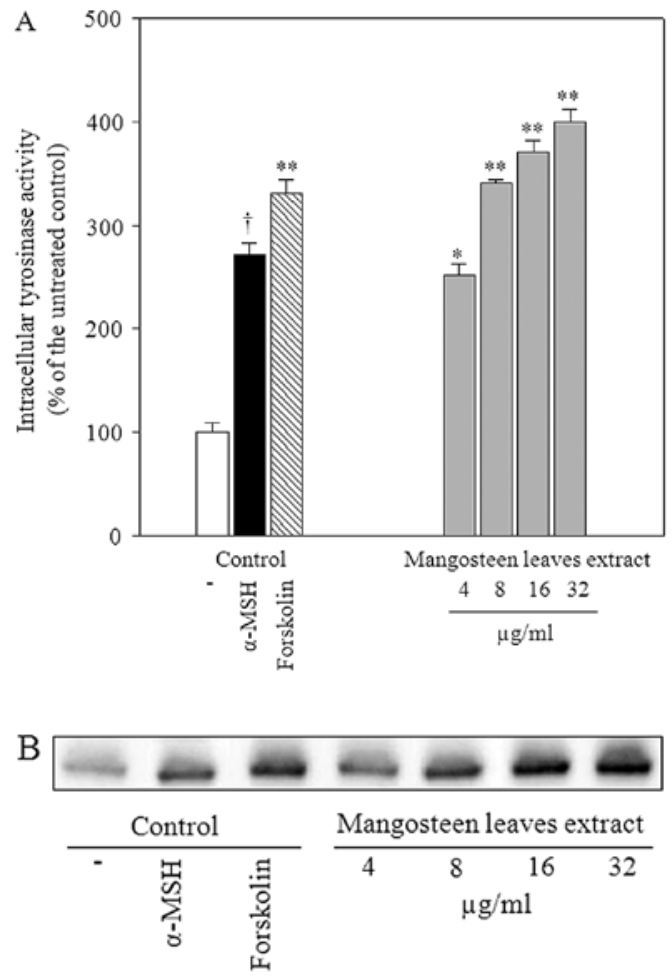

Figure 4. Activation and increase of intracellular tyrosinase activity of B16F1 melanoma cells by mangosteen leaf extract. (A) Mangosteen leaf extract (ML) treatment effectively increased intracellular tyrosinase activity. Upon treatment with $\alpha-\mathrm{MSH}$, the intracellular tyrosinase activity of the B16F1 melanoma cells increased by 2-fold, a significant increase compared to the negative control group, while treatment with forskolin increased intracellular tyrosinase activity by 2.3 -fold. Further treatment by $32 \mu \mathrm{g} / \mathrm{ml}$ ML increased the intracellular tyrosinase activity by 2.8 -fold. (B) Increased tyrosinase activity by the ML was confirmed through tyrosinase zymography in order to identify the active form of the tyrosinase. The role of ML in the stimulation of activated tyrosinase in B16F1 melanoma cells was examined. The tyrosinase zymography results show a dark, stained tyrosinase band after treatment with $\alpha$-MSH. The band became darker by treatment with forskolin; treatment with the ML at a concentration of $32 \mu \mathrm{g} / \mathrm{ml}$ resulted in increased intensity of the band. These results confirmed that there was an increment in tyrosinase activity in ML-treated cells. Results are the average of three independent experiments $\pm \mathrm{SD}$. ${ }^{*} \mathrm{P}<0.05,{ }^{* *} \mathrm{P}<0.01$ compared to $(+) \alpha$-MSH control.

the mangosteen leaf extract increased the melanogenesis activity of the B16F1 melanoma cells.

Melanogenic effect of mangosteen leaf extract on intracellular tyrosinase activity of B16F1 melanoma cells. Melanogenesis is regulated by the activity of tyrosinase, a rate-limiting enzyme in melanin biosynthesis (13). Since melanin is derived from the precursor dopaquinone that is formed by tyrosinase oxidation of L-tyrosine, tyrosinase plays an important role in melanin synthesis. Increased tyrosinase activity in melanocytes could be achieved either by direct inhibition of tyrosinase itself or stimulation of tyrosinase gene expression, leading to increased amounts of the protein level in cells. Thus, in this study, the authors examined the effects of the mangosteen leaf extract on tyrosinase activity. To elucidate the mechanism of melanogenesis stimulated by the extract, B16F1 melanoma cells were treated with the extract at similar concentrations, with those of the melanin assay. Each percentage value of tyrosinase activity in the treated cells was calculated with respect to the control group. The same amount of cell lysate calibrated with respect to protein concentration was applied to the oxidation reaction with L-DOPA. Upon treatment with $\alpha-\mathrm{MSH}$, the intracellular tyrosinase activity of the B16F1 cells increased 2.5-fold as shown in Fig. 4A. Treatment with FK significantly increased the intracellular tyrosinase activity more than 3-fold, while treatment with $32 \mu \mathrm{g} / \mathrm{ml}$ of the extract clearly demonstrated a 4-fold increase in intracellular tyrosinase activity. This observation is consistent with the fact that they are known to be direct tyrosinase stimulators and as a result, confirmed that increases in melanin synthesis were accompanied by increased tyrosinase activity. In parallel with the secreted melanin levels, the intracellular tyrosinase activity was also increased dosedependently by the extract.

Mangosteen leaf extract induces tyrosinase gene expression by tyrosinase zymography. In order to clarify the further mechanism of tyrosinase activation by the mangosteen leaf extract, the levels of tyrosinase expression in the B16F1 melanoma cells were examined by tyrosinase zymography. Tyrosinase activity can also be analyzed after separation by SDS-PAGE. Tyrosinase separation based on the molecular weight on a gel indicates its enzymatic activity by observing the oxidation of the L-DOPA solution applied on the gel to form dark-colored dopaquinone (38). $\alpha$-MSH treatment created a dark-black band compared to that of untreated control. FK treatment created darker black bands than $\alpha-\mathrm{MSH}$ or the treated control (Fig. 4B). Meanwhile, treatment with $32 \mu \mathrm{g} / \mathrm{ml}$ of the ML extract resulted in a very distinct and the darkest black band. Treatment with $8 \mu \mathrm{g} / \mathrm{ml}$ of the ML extract yielded a black band similar and comparable to that with $\alpha-\mathrm{MSH}$ treatment, while treatment with $16 \mu \mathrm{g} / \mathrm{ml}$ of the extract gave a black band darker than that obtained by treatment with FK. From this observation, the results proved that tyrosinase zymography seemed to correlate well with measurement of intracellular tyrosinase activity.

Immunoblotting shows up-regulation of MITF and tyrosinase expression. Melanin is synthesized in melanosomes, which harbor the specific enzymes required for melanin production. Among them, the tyrosinase gene family has been determined to perform a crucial role in melanogenesis regulation (39). Tyrosinase, the specific enzyme that catalyzes the rate-limiting step for melanin biosynthesis, is a well-characterized marker of differentiation in melanocytes and melanoma cells. MITF has a basic-helix-loop-helix (b-HLH) and b-HLH-leucine zipper motif, a dominant transcription factor critical for melanogenic expression, and plays an essential role for regulation at the transcription level in melanogenesis of tyrosinase, tyrosinase-related protein 1 (TRP-1), and tyrosinase-related protein 2 (TRP-2) (16). Thus, activation of MITF is known to be a critical event in melanogenesis (17). Up-regulation of melanin synthesis-related components like tyrosinase and MITF result in increments of melanin synthesis. Thus, to investigate the mechanism of mangosteen leaf extract-induced melanogenesis, we examined the effects of the extract on the expression of melanogenic proteins such as tyrosinase and MITF, via determinations of tyrosinase and MITF genes using immunoblot analysis. In this experiment, the similar $\beta$-actin expressions obtained indicate that the same amount of protein was loaded during SDS-PAGE (Fig. 5). The marked enhancement of the 75-kDa tyrosinase upon treatment with $\alpha-\mathrm{MSH}$ and 

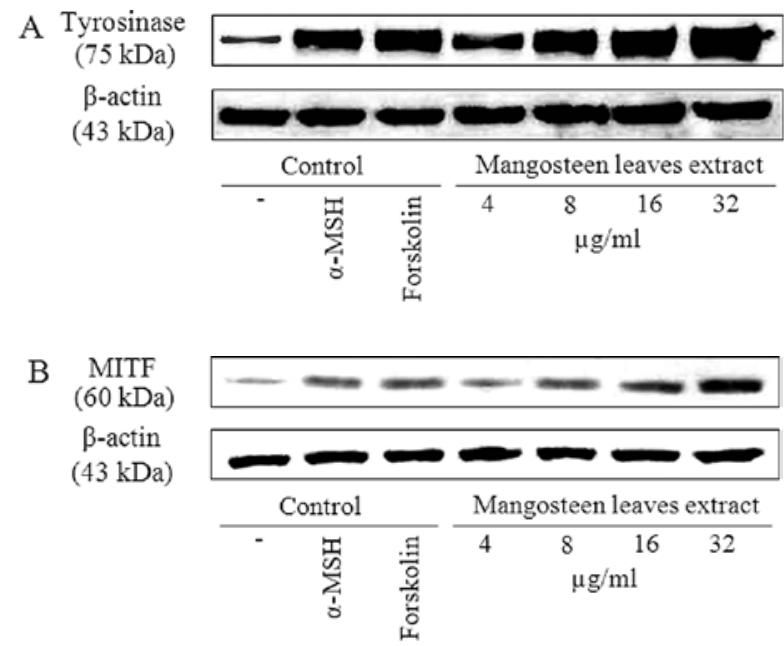

Figure 5. Tyrosinase and MITF expressions detected by immunoblotting. (A) Tyrosinase expression was shown to increase. $\beta$-actin expression was used to indicate equal protein loading in all lanes. Protein expression of tyrosinase and MITF increased by treatment with mangosteen leaf extract (ML). ML mimics the melanogenesis stimulators, increasing tyrosinase and MITF expression, which directly regulates melanin synthesis. (B) Western blotting indicates that MITF expression increases by ML treatment. $\beta$-actin expression was used to verify that equal amounts of protein were loaded in all lanes. MITF is a key transcription regulator, which is related to activation of melanogenic proteins like tyrosinase. ML increases melanogenesis by upregulating MITF expression.

FK correlated well with an increase in intracellular tyrosinase activity under identical conditions. The level of tyrosinase and MITF expressions increased markedly after treatment with the extract (Fig. 5A). MITF and tyrosinase protein expressions gradually increased in a dose-dependent manner, indicating that both protein expressions correlated well and were in agreement with increase in melanin synthesis (Fig. 2A-C) and tyrosinase activity (Fig. 3). The MITF and tyrosinase expressions for cells treated with mangosteen leaf extract seemed to be very distinct and darker compared to the cells treated only with $5 \mathrm{nM} \alpha-\mathrm{MSH}$ and $10 \mu \mathrm{M} \mathrm{FK}$. The results indicate that up-regulation of tyrosinase gene expression by the ML extract could be due to increased levels of MITF. However, whether this increments of the MITF protein were caused by induced expression of the MITF gene were not determined in this experiment.

Studies have found that upstream effectors regulate MITF, including extracellular signal-regulated kinase (ERK), phosphatidylinositol 3-kinase (PI3K), and glycogen synthase kinase $3 \beta$ (GSK3 $\beta)(16,40,41)$.

\section{Discussion}

Previous studies from other groups show that bee venom increases melanogenesis in human melanocytes (42). Furthermore, it has been shown that extracts from some herbs, including kava rhizome extract (43), glycyrrhizin (44), lotus flower (45), cubebin (46), quercetin (47) and naringenin (17) increase melanogenesis in B16 melanoma cells and human melanocytes, thereby indicating that natural resources should be extensively screened for the development of gray hair prevention agents or therapeutic drugs to induce repigmentation in the skin of vitiligo patients.
In accordance with a tendency of increasing demand to overcome the problems regarding hypopigmentation and vitiligo, the mangosteen leaf extract was evaluated for the possibility of inducing melanogenic efficacy using cultured B16F1 melanoma cells. In this study, the effects of the mangosteen leaf extract were evaluated by a skin pigmentation induction and a melanin assay, by an intracellular tyrosinase assay, tyrosinase zymography, and by immunoblotting to prove that ML remarkably induced melanin synthesis in cultured $\mathrm{B} 16 \mathrm{~F} 1$ melanoma cells and restrained it at a concentration of $32 \mu \mathrm{g} / \mathrm{ml}$, an effect which was more potent than that produced by $5 \mathrm{nM} \alpha-\mathrm{MSH}$ or $10 \mu \mathrm{M} \mathrm{FK}$.

The ML extract was shown to enhance melanin synthesis in B16F1 melanoma cells in a dose-dependent manner. B16F1 melanoma cells, after treatment with mangosteen leaf extract, showed a more than 2-fold increase in secreted melanin and intracellular tyrosinase activity, indicating that this extract can be one of the melanogenic-stimulation agents. Furthermore, the intracellular tyrosinase activity resulted from the ML extract acting as a stimulator of tyrosinase oxidation. Tyrosinase zymography, a method to identify intracellular tyrosinases, proved that intracellular tyrosinase was stimulated by the ML extract more efficiently than with $\alpha-\mathrm{MSH}$ or FK. The ML extract elevated the level of tyrosinase expression and resulted in very dark and distinct band via tyrosinase zymography. In addition, the expression levels of tyrosinase and MITF via immunoblot analysis indicated that the mangosteen leaf extract may be a promising candidate capable of stimulating melanogenesis by up-regulation of cellular tyrosinase activity and direct catalytic process. Select mangosteen leaf extract concentrations ( 16 and $32 \mu \mathrm{g} / \mathrm{ml}$ ) were found to be more potent than $5 \mathrm{nM} \alpha$-MSH or $10 \mu \mathrm{M}$ FK in inducing the melanogenic effects of B16F1 melanoma cells. Thus, the presented results indicate that the mangosteen leaf extract may be useful towards treatment of hypopigmentation disorder, in the development of gray hair prevention agents, and useful for self-tanning cosmetics products. Future studies will focus on identifying active compounds responsible for this melanogenic activity and mechanical study of the melanogenesis pathway of the mangosteen leaf extract.

\section{Acknowledgements}

The authors would like to acknowledge Dr Songhee Jun, DURIB Dongguk University, for her critical discussions and technical advice regarding this study.

\section{References}

1. Martin FW: Durian and mangosteen. In: Tropical and Subtropical Fruits: Composition, Properties and Uses. Nagy S and Shaw DE (eds). AVI Publishing, Westport, pp407-414, 1980.

2. Moongkarndi P, Kosem N, Kaslungka S, Luanratana O, Pongpan N and Neungton N: Antiproliferation, antioxidant and induction of apoptosis by Garcinia mangostana (mangosteen) on SKBR3 human breast cancer cell line. J Ethnopharmacol 90: 161-166, 2004.

3. Mahabusakaram W, Iriyachitra P and Taylor WC: Chemical constituent of Garcinia mangostana. J Nat Product 50: 474-478, 1987.

4. Jiang DJ, Dai Z and Li YJ: Pharmacological effects of xanthones as cardiovascular protective agents. J Cardiovasc Drug Rev 22: 91-102, 2004 
5. Jung HA, Su BN, Keller WJ, Mehta RG and Kinghorn AD Antioxidant xanthone from the pericarp of Garcinia mangostana (Mangosteen). J Agric Food Chem 54: 2077-2082, 2006.

6. Liao CH, Sang S, Liang YC, Ho CT and Lin JK: Suppression of inducible nitric oxide synthase and cylooxygenase- 2 in down regulating nuclear factor- $\mathrm{\kappa B}$ pathway by garcinol. Mol Carcinog 41: 140-149, 2004.

7. Nakatani K, Nakahata N, Arakawa T, Yasuda $\mathrm{H}$ and Ohizumi $\mathrm{Y}$ : Inhibition of cyclo-oxygenase and prostaglandin $\mathrm{E}_{2}$ synthesis by $\gamma$-mangostin, a xanthone derivative in mangosteen, in C6 rat glioma cells. Biochem Pharmacol 63: 73-79, 2002.

8. Sampath PD and Vijayaraghavan K: Cardioprotective effect of $\alpha$-mangostin, a xanthone derivative from mangosteen on tissue defense system against isoproterinol-induced myocardial infarction in rats. J Biochem Mol Toxicol 21: 336-339, 2007.

9. Sunit S, Narisara S, Wong P, Janthana T, Piniti R, Nitirat C and Apichart S: Antimycobacterial activity of prenylated xanthone from the fruits of Garcinia mangostana. Chem Pharm Bull (Tokyo) 51: 857-859, 2003.

10. Nabandith V, Suzui M, Morioka T, Kaneshiro T, Kinjo T, Matsumoto K, Akao Y, Inuma M and Yoshimi N: Inhibitory effects of crude alpha-mangosteen, a xanthone derivative, on two different categories of colon preneoplastic lesions induced by 1,2-dimethylhydrazine in the rat. Asian Pac J Cancer Prev 5 : 433-438, 2004

11. Yokota T, Nishio H, Kubota Y and Mizoguchi M: The inhibitory effect of glabridin from licorice extracts on melanogenesis and inflammation. Pigment Cell Res 11: 355-361, 1998.

12. Garcia-Borron JC, Sanchez-Laorden BL and Jimenez-Cervantes C: Melanocortin-1 receptor structure and functional regulation. Pigment Cell Res 18: 393-410, 2005.

13. Schallreuter KU, Kothari S, Hasse S, Kauser S, Lindsey NJ, Gibbons NC, Hibberts N and Wood JM: In situ and in vitro evidence for $\mathrm{DCoH} / \mathrm{HNF}-1$ alpha transcription of tyrosinase in human skin melanocytes. Biochem Biophys Res Commun 301: 610-616, 2003

14. Kim TJ, Cho MK, Lee JS, Whang KU, Jin SY and Hoshino T: The expression of melanogenic proteins in Korean skin after ultraviolet irradiation. J Dermatol 30: 665-672, 2003.

15. Slominski A, Szczesniewski A and Wortsman J: Liquid chromatography-mass spectrometry detection of corticotropin-releasing hormone and proopiomelanocortin-derived peptides in human skin. J Clin Endocrinol Metab 85: 3582-3588, 2000.

16. Busca R and Ballotti R: Cyclic AMP a key messenger in the regulation of skin pigmentation. Pigment Cell Res 13: 60-69, 2000.

17. Connor $\mathrm{M}$ and Christie MJ: Opioid receptor signalling mechanisms. Clinical Exp Pharmacol Physiol 26: 493-499, 1999.

18. Park HY, Wu C, Yonemoto L, Murphy-Smith M, Wu H Starchur CM and Gilchrest BA: MITF mediates cAMP-induced protein kinase C-beta expression in human melanocytes. Biochem J 395: 571-578, 2006.

19. Tachibana M: MITF: a stream flowing for pigment cells. Pigment Cell Res 13: 230-240, 2000.

20. Choi H, Ahn S, Lee BG, Chang I and Hwang JS: Inhibition of skin pigmentation by an extract of Lepidium apetalum and its possible implication in IL-6 mediated signaling. Pigment Cell Res 18: 439-446, 2005

21. Chung SW, Ha YM, Kim YJ, Song S, Lee H, Suh H and Chung HY: Inhibitory effects of 6-(3-hydroxyphenyl)-2-naphthol on tyrosinase activity and melanin synthesis. Arch Pharm Res 32: 289-294, 2009

22. Costin GE and Hearing VJ: Human skin pigmentation: melanocytes modulate skin color in response to stress. FASEB J 21: 976-994, 2007

23. Englaro W, Bertolotto C, Busca R, Brunet A, Pages G, Ortonne JP and Balloti R: Inhibition of the mitogen-activated protein kinase pathway triggers B16 melanoma cell differentiation J Biol Chem 273: 9966-9970, 1998 .

24. Hearing VJ: Biogenesis of pigment granules: a sensitive way to regulate melanocyte function. J Dermatol Sci 37: 3-14, 2005.

25. Seiberg M, Paine C, Sharlow E, Andrea-Gordon P, Costanzo M, Eisinger $M$ and Shapiro SS: Inhibition of melanosome transfer results in skin lightening. J Invest Dermatol 115: 162-167, 2000.

26. Kobayashi T and Hearing VJ: Direct interaction of tyrosinase with Tyrp1 to form heterodimeric complexes in vivo. J Cell Sci 120: 4261-4268, 2007.

27. Kim DS, Park SH, Kwon SB, Park ES, Huh CH, Youn SW and Park KC: Sphingosylphosphorylcholine-induced ERK activation inhibits melanin synthesis in human melanocytes. Pigment Cell Res 19: 146-153, 2006.
28. Miyamura Y, Coelho SG, Wolber R, Miller SA, Wakamatsu K, Zmudzka BZ, Ito S, Smuda C, Passeron T, Choi W, Batzer J, Yamaguchi Y, Beer JZ and Hearing VJ: Regulation of human skin pigmentation and responses to ultraviolet radiation. Pigment Cell Res 20: 2-13, 2007.

29. Xu WD, Gong L, Haddad MM, Bischof O, Campisi J, Yeh ET and Medrano EE: Regulation of microphthalmia-associated transcription factor MITF protein levels by association with the ubiquitin-conjugating enzyme hUBC9. Exp Cell Res 255: $135-143,2000$.

30. Lassalle MW, Igarashi S, Sasaki M, Wakamatsu K, Ito S and Horikoshi T: Effects of melanogenesis-inducing nitric oxide and histamine on the production of eumelanin and pheomelanin in cultured human melanocytes. Pigment Cell Res 16: 81-84, 2003.

31. Nath SK, Majumder PP and Nordlund JJ: Genetic epidemiology of vitiligo: multilocus recessivity cross-validated. Am J Hum Genet 55: 981-990, 1994.

32. Grimes PE: New insights and new therapies in vitiligo. JAMA 293: 730-735, 2005.

33. Choi HK, Kim DH, Kim JW, Ngadiran S, Sarmidi MR and Park CS: Labisia pumila extract protects skin cells from photoaging caused by UVB irradiation. J Biosci Bioeng 109: 291-296, 2010.

34. Bhatnagar V, Srirangam A and Abburi R: In vitro modulation of proliferation and melanization of melanoma cells by citrate. Mol Cell Biochem 187: 57-65, 1998.

35. Oh MJ, Hamid MA, Ngadiran S, Seo YK, Sarmidi MR and Park CS: Ficus deltoidea (Mas cotek) extract exerted anti-melanogenic activity by preventing tyrosinase activity in vitro and by suppressing tyrosinase gene expression in $\mathrm{B} 16 \mathrm{~F} 1$ melanoma cells. Arch Dermatol Res 303: 161-170, 2011.

36. Kim KS, Kim JA, Eom SY, Lee SH, Min KR and Kim Y: Inhibitory effect of piperlonguminine on melanin production in melanoma B16 cell line by downregulation of tyrosinase expression. Pigment Cell Res 19: 90-98, 2006.

37. Oka M, Ichihashi M and Chakraborty AK: Enhanced expression of protein kinase $\mathrm{C}$ subspecies in melanogenic compartments in B16 melanoma cells by UVB or MSH. J Invest Dermatol 106: 377-378, 1996.

38. Sato K, Takahashi H, Iraha R and Toriyama M: Down-regulation of tyrosinase expression by acetylsalicylic acid in murine B16 melanoma. Biol Pharm Bull 31: 33-37, 2008.

39. Pawalek JM and Murray M: Increase in melanin formation and promotion of cytotoxicity in cultured melanoma cells caused by phosphorylated isomers of L-Dopa. Cancer Res 46: 493-497, 1986.

40. Busca R, Bertolotto C, Ortonne JP and Balloti R: Inhibition of the phosphatidylinositol 3-kinase/p70(S6)-kinase pathway induces B16 melanoma cell differentiation. J Biol Chem 271: 31824-31830, 1996.

41. Khaled M, Larribere L, Bille K, Aberdam E, Ortonne JP and Balloti R and Bertolotto C: Glycogen synthase kinase 3beta is activated by cAMP and plays an active role in the regulation of melanogenesis. J Biol Chem 277: 33690-33697, 2002.

42. Jeon S, Kim NH, Koo BS, Lee HJ and Lee AY: Bee venom stimulates human melanocyte proliferation, melanogenesis, dendrity and migration. Exp Mol Med 39: 603-613, 2007.

43. Matsuda H, Hirata N, Kawaguchi Y, Naruto S, Takata T, Oyama M, Iinuma $\mathrm{M}$ and Kubo M: Melanogenesis stimulation in murine B16 melanoma cells by kava (Piper methysticum) rhizome extract and kavalactones. Biol Pharm Bull 29: 834-837, 2006.

44. Jung GD, Yang JY, Song ES and Par JW: Stimulation of melanogenesis by glycyrrhizin in B16F1 melanoma cells. Exp Mol Med 33: 131-135, 2001.

45. Jun S, Kim NH, Koo BS, Kim JY and Lee AY: Lotus (Nelumbo nucifera) flower essential oil increased melanogenesis in normal human melanocytes. Exp Mol Med 41: 517-524, 2009

46. Hirata N, Naruto S, Ohguchi K, Akao Y, Nozawa Y, Iinuma M and Matsuda H: Mechanism of the melanogenesis stimulation activity of (-)-cubebin in murine B16 melanoma cells. Bioorg Med Chem 15: 4897-4902, 2007.

47. Nagata H, Takekoshi S, Takeyama R, Homma T and Osamura R Quercetin enhances melanogenesis by increasing the activity and synthesis of tyrosinase in human melanoma cells and normal human melanocytes. Pigment Cell Res 17: 66-73, 2004.

48. Kenji O, Yukihiro A and Yoshinori N: Stimulation of melanogenesis by the citrus flavanoid naringenin in mouse B16 melanoma cells. Biosci Biotechnol Biochem 70: 1499-1501, 2006. 